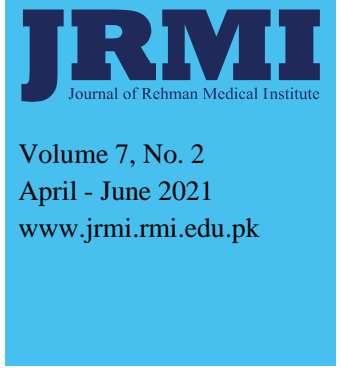

Submitted

February 13, 2021

Accepted

April 16, 202

\section{Author Information}

Ms. Saba Yaqoob

Senior Lecturer

Nur International University

(Corresponding Author)

Email:

sabayaqoob31@gmail.com

Dr. Nayab Iftikhar

Assistant Professor

University of The Punjab

From: The University of Lahore, Lahore, Punjab, Pakistan

Ms. Hafsa Noreen

Assistant Professor

\section{Ms. Rabia Qamar}

Lecturer

Mr. Azzam Khan

Lecturer

Ms. Amna Rashid

Senior Lecturer

Citation: Yaqoob S, Iftikhar N, Noreen H, Qamar R, Khan A, Rashid A. Assessment of quality of life in patients with aphasia. J Rehman Med Inst. 2021 Apr-Jun;7(2):20-3

\title{
Assessment of quality of life in patients with aphasia
}

\author{
Saba Yaqoob, Nayab Iftikhar, Hafsa Noreen, Rabia Qamar, Azzam Khan, Amna Rashid
}

\section{ABSTRACT}

Introduction: Personal satisfaction (Quality of Life; QoL) is the person's impression of their own prosperity. Aphasia is the most significant likely result of stroke and profoundly affects a patient's life, causing enthusiastic pain, sadness, and social separation, because of loss of language capacities.

Objective: To document personal satisfaction in patients with aphasia.

Materials \& Methods: A cross sectional study was conducted at a Speech Clinic from October 2018 to March 2019 on 57 patients of aphasia to assess their quality of life. Informed consent was taken from respondents. Patients having aphasia due to any neurological cause or traumatic brain injury were included in study, while patients having childhood aphasia were excluded. Standardized questionnaire "Measuring changes in Quality of life in persons with aphasia: Is Communication Confidence a good measure?" was used to obtain information from participants through purposive sampling. Data were collected by face to face interviews with patients and their caregivers. Descriptive data analysis was done through SPSS

Results: Majority (68.42\%) of respondents did not feel confident about their ability to convey meaning via speech with people. Difficulties in social communication were also a reason of concern for $45.61 \%$ participants, whereas $50.87 \%$ participants stated that they could not make their decisions.

Conclusion: Patients suffering from aphasia had low quality of life, mainly due to their communication disabilities and dependence on other people for understanding, as well as the fact that their caretakers had to take decisions for them.

Keywords: Aphasia; Health-Related Quality of Life; Language Disorders; Speech-Language Pathology; Stroke.

The authors declared no conflict of interest. All authors contributed substantially to the planning of research, data collection, data analysis, and write-up of the article, and agreed to be accountable for all aspects of the work.

\section{INTRODUCTION}

Aphasia is a language disability described as a breakdown in capacity to define, recover or interpret the dynamic images of language. Its beginning is generally abrupt, happening without disturbing an individual who has no past attack or language issues. Aphasia can occur due to any reason like trauma, tumor, or neurologic disease, most commonly stroke. Which particular site of damage produces which type of aphasia is still controversial; limited knowledge is available to speculate about cortical damage and aphasia. There are a number of classifications to categorize aphasia. One classification is based on a person's ability to produce speech, and has two types: fluent aphasia and non-fluent aphasia. ${ }^{1}$

Fluent aphasia is named after the word fluency that means without any hindrance. A person with fluent aphasia usually has no difficulty in speaking but the ability to understand or comprehend is impaired. Such a person is usually unaware about speech errors and produces meaningless speech. ${ }^{2}$ Nonfluent aphasia is present when a person has severe difficulty in speaking but cognition is usually intact. Patient's speech is sparse and limited. In severe cases patient can only vocalize to communicate. In some cases patient can say few words. Most of the patients with non-fluent aphasia are depressed because they know and understand what is happening, and know what they want to say, but they are unable to do so. ${ }^{2}$

Quality of life is a concept that is considered increasingly important for assessment of rehabilitation. The notion of "quality of life" is used both in the sense of subjective feelings and attitudes, and in the sense of absence or presence of complaints resulting from disability or handicap. Thus, when subjects are asked to rate their quality of life, it may be related to emotional states, to physical and psychosocial abilities, or to all of them. ${ }^{3}$

A Speech and Language Pathologist designs a therapy program according to the abilities of individual clients and considering the capacities of rehabilitation facility and availability of caregiver support. In order to design a therapy program, willpower and compliance of patient matters a lot. Stronger the willpower, greater are the chances of patient's recovery. If patient is not motivated therapist cannot do anything despite continuous sessions. $^{4}$ 
A study was directed by Katerina Hilari and Sally Byng in $2009^{5}$ "Health-related personal satisfaction in individuals with serious aphasia". A poll based cross sectional review was completed where intermediaries of individuals with serious aphasia gave an account of their Health Related Quality of Life (HRQL). Individuals with serious aphasia's personal satisfaction was low and more than one standard deviation beneath that of the normalization test of the Stroke and Aphasia Quality of life scale (SAQOL). The general mean score for the SAQOL-39 and the methods for its physical and correspondence spaces were underneath the twentieth centile. They were likewise altogether lower than those of the correlation investigations of self-reports $(n=83)$ and intermediary appraisals $(n=50)$ of individuals with mellow or moderate aphasia $(\mathrm{p} \leqslant 0.003)$.

In 2004 Ilknur Mavis, Anadolu University, Center for Speech and Language disorders conducted a study ${ }^{6}$ to assess the quality of life in patients of aphasia and their family members. They took 196 patients of aphasia. Questionnaire was used for this study. It was concluded that quality of life in aphasia is poor and strong action is required to improve quality of life in patients of aphasia.

Another study ${ }^{7}$ was conducted by Anderson and Tranel on quality of life in 100 aphasic patients following cerebral infarction and head trauma using standardized "Awareness Interview" questionnaire. It was concluded that patients experienced "unawareness" of their aphasic states associated with intellectual impairment, leading to decline in quality of life that needed a lot of hard work to fill the gap.

Another study was conducted at Auckland in $2013^{8}$ by McCann, Tunnicliffe and Anderson on 200 patients to investigate the quality of life in patients of aphasia. A brief questionnaire was used to obtain information from participants. Conclusion was that quality of life in patients of aphasia is disappointingly low.

The present study was conducted to bridge the literature gap and to assess the quality of life in patients with aphasia in local settings, so that recommendations can be suggested accordingly and required immediate measures could be taken.

\section{MATERIALS \& METHODS}

This study was conducted at Speech Clinic of Riphah College of Rehabilitation \& Allied Health Sciences, Riphah International University. This study was conducted in duration of six months from October 2018 to March 2019. Cross sectional study design was used for this study. Standardized questionnaire was used to collect data namely "Measuring
Changes in Quality of Life in Persons with Aphasia". ${ }^{9}$ Patients or their family members were briefed about study and objectives of study. Data was collected from patients or their family members through questionnaire. Questionnaire consisted of 17 items. Consent was obtained in written from. Respondents were briefed about procedure and importance of study. Demographic information was obtained in first section of questionnaire. Second section focused on assessment of quality of life in patients with aphasia. Incidence of aphasia is 250/100,000 in Pakistan. ${ }^{10}$ Sample size for this study was 57 patients that was calculated on the basis of available literature. ${ }^{11}$ It was calculated by using online sample size calculator keeping $90 \%$ confidence interval and $10 \%$ margin of error. Purposive Sampling technique was used for this study. Patients having aphasia after stroke and Traumatic brain injury were included in this study. Patients who had aphasia in comorbidity with degenerative disease or childhood aphasia were excluded. SPSS was used for data analysis and Endnote was used for referencing.

\section{RESULTS}

Total 57 participants participated in this study, Out of which 38 $(66.67 \%)$ were male and $19(33.3 \%)$ were female. Mean age of participants was 68.9 years.

Out of 57 participants who responded in this study 15(25.9\%) patients were suffering from Broca's aphasia, 21(36.2\%) were suffering from Wernicke's aphasia, 15(25.9\%) had anomic aphasia patients, and 06(12\%) patients were suffering from global aphasia (Table 1).

Table 1: Type of Aphasia in subjects $(n=57)$.

\begin{tabular}{|l|c|}
\hline \multicolumn{1}{|c|}{ Type of Aphasia } & $\mathbf{f}(\%)$ \\
\hline Broca's Aphasia & $15(25.9)$ \\
\hline Wernicke's Aphasia & $21(36.2)$ \\
\hline Anomic Aphasia & $15(25.9)$ \\
\hline Global Aphasia & $06(12)$ \\
\hline
\end{tabular}

Table 2 depicts responses of patients to the Quality of Life questions. It was observed that $68.42 \%$ respondents were not confident about their ability to talk with people; $42.10 \%$ respondents showed that their ability to stay in touch with family and friends was compromised; $45.61 \%$ respondents reported that their social communication was impaired; $52.6 \%$ participants stated that they could not speak for themselves; and $50.87 \%$ respondents stated that they were not able to make their own decisions.

Table 2: Questionnaire on Quality of Life in Aphasia.

\begin{tabular}{|l|l|c|c|c|c|}
\hline$\#$ & \multicolumn{1}{|c|}{ Questions } & Not Confident & $\begin{array}{c}\text { Moderately } \\
\text { Confident }\end{array}$ & $\begin{array}{c}\text { Very } \\
\text { Confident }\end{array}$ & Total \\
\hline 1. & Ability to stay in touch with family and friends & $24(42.10)$ & $18(31.8)$ & $15(26.31)$ & $57(100)$ \\
\hline 2. & Ability to talk with people & $39(68.42)$ & $4(7.01)$ & $14(24.5)$ & $57(100)$ \\
\hline 3. & Ability to get involved in conversations & $26(45.61)$ & $15(26.31)$ & $16(28.07)$ & $57(100)$ \\
\hline 4. & Ability to follow news, sports and stories on TV/Movie & $24(42.10)$ & $14(24.56)$ & $19(33.33)$ & $57(100)$ \\
\hline 5. & Ability to speak on telephone & $28(49.12)$ & $11(19.29)$ & $18(31.57)$ & $57(100)$ \\
\hline 6. & Ability to be understood by people when you talk & $22(38.59)$ & $15(26.31)$ & $20(35.08)$ & $57(100)$ \\
\hline 7. & Ability to make your own decision & $29(50.87)$ & $10(17.54)$ & $18(31.57)$ & $57(100)$ \\
\hline 8. & Ability to speak for yourself & $30(52.6)$ & $20(35.08)$ & $7(10.5)$ & $57(100)$ \\
\hline
\end{tabular}




\section{DISCUSSION}

This study was conducted to determine the quality of life in patients of Aphasia. The study addressed different domains that reflect the quality of one's life. Patients' responses showed that quality of life in aphasia is compromised and this issue needs to be addressed. To communicate with people one needs to express thoughts by putting them in words. Respondents highlighted that they did not feel confident while speaking after having aphasia. Their ability to communicate with people had been compromised, and $68.42 \%$ respondents showed that it was a huge barrier to better quality of life as someone not able to speak coherently definitely has their quality of life compromised.

For a person to share opinions, views, ideas and thoughts it is very important to actively take part in ongoing conversations. Results of this study reflected that people with aphasia did not feel very comfortable about taking part in conversations, as $42.10 \%$ participants felt that their ability to stay in touch with family and friends was impaired. Results reflected that most of the times normal people did not include patients of aphasia in their conversations. This study reflected that lack of communication abilities by patients of aphasia led to social isolation and ultimately compromising the quality of life.

Most of the respondents provided information that reflected that they feel low due to their less involvement in social activities like communication and taking part in conversations that leads to low quality of life in patients with aphasia. $45.61 \%$ participants reflected that their social communication is impaired. The findings of this research are consistent with the results of a study conducted in 2008 on Social participation of older patient with aphasia, according to which people with aphasia communicated with fewer friends and had smaller social networks. ${ }^{12}$

Entertainment in life have a positive effect on wellbeing of every individual results of this study reflected that people suffering from aphasia are not very confident about their abilities to follow to news, sports, and stories on TV/ movies this is more common in fluent aphasia's. $42.10 \%$ respondents found it difficult to follow news, sports and movies As to follow any sports a person should have sound understanding of that sports but in fluent aphasia comprehension is usually impaired therefore it is not possible for a person suffering from aphasia to comprehend and enjoy sports or movies on television. ${ }^{13}$

This study found that people who suffer from aphasia find it difficult to speak on the telephone. This can apply to both fluent and non-fluent aphasia as people with non- fluent aphasia are not able to speak and people with fluent aphasia may not be able to comprehend thus miserably compromising the quality of life. ${ }^{14}$

Results of this showed that people with aphasia are not confident that people understand them when they speak. Results of $38.59 \%$ participants showed that most of the patients feel very low about their communication abilities most of the patients believe that people do not understand them when they try to speak or they try to convey their message mostly people do not understand the intended message and thus patients are left out of conversations making then frustrated which can lead to stress or depression as well thus this point highlight that quality of life in patients of aphasia is highly compromised. ${ }^{15}$

Making decisions is a very important aspect of life be it making a choice about what to eat in breakfast, what to wear, where to go or a decision about treatment preferences. Results of this study showed that patients having aphasia feel very low about their ability to take part in decision making; this may be partially because of their impaired comprehension or it can also be due to their impaired ability to speak. Irrespective of the reason, it has serious impact on the quality of life of patients with aphasia. ${ }^{16}$

This study also addressed that how people with aphasia feel about their ability to speak for themselves.52.6\% participants stated that they are not very confident about their ability to speak for themselves this is major hallmark that represents that quality of life in aphasia is very low as people with aphasia are in constant need of someone who can understand them, their needs and also can convey their intended message. As the results indicate that people with aphasia are not very confident about their decision making abilities thus the results reflect that person with aphasia live a low quality of life as they are deprived of the elements that can contribute to improved life quality but unfortunately their quality of life is below average. ${ }^{17}$

A study was conducted by Hilari K et a ${ }^{18}$ in 2015 on Quality of life in aphasia: state of the art; the study showed that quality of life in patients with aphasia is very low. This study endorses the results of current study that quality of life in patients with aphasia is very low.

To communicate with people one needs to express thoughts by putting them in words; respondents highlighted that they did not feel confident while speaking after having aphasia as their ability to communicate with people had been compromised. This was a huge barrier to provision of a better quality of life for the affected patients.

\section{CONCLUSION}

It is concluded that quality of life in aphasia is highly compromised due to lack of confidence and inability to express thoughts and emotions in words, thereby compromising social interactions.

\section{RECOMMENDATION}

It is recommended that measures should be taken to improve quality of life in patients with aphasia so that they can actively participate in daily life and be fruitful citizens of society. 


\section{REFERENCES}

1. LaPointe LL. Quality of life with aphasia Semin Speech Lang. 1999;20(1):5-16; quiz 16-7. doi: 10.1055/s-2008-1064005.

2. Edwards S. Fluent aphasia. Cambridge University, UK: Cambridge University Press; 2005.

3. Hilari K, Byng S, Lamping DL, Smith SC. Stroke and aphasia quality of life scale-39 (SAQOL-39) evaluation of acceptability, reliability, and validity. Stroke. 2003;34(8):1944-50.

4. Ross K, Wertz R. Quality of life with and without aphasia. Aphasiology. 2003;17(4):355-64.

5. Hilari K, Byng S. Health-related quality of life in people with severe aphasia. Int J Lang Commun Disord. Mar-Apr 2009;44(2):193-205.

6. Mavis I. Awareness of stroke and aphasia among Turkish patients in a neurology unit. Clin Linguist Phon. 2007;21(1):55-70.

7. Anderson WS, Tranel D. Awareness of disease states following cerebral infarction, dementia, and head trauma: Standardized assessment. Clinical Neuropsychologist. 1989;3(4):327-39. Published Online. 2007. Available from: http://dx.doi.org/10.1080/13854048908401 482 .
8. McCann C, Tunnicliffe K, Anderson R. Public awareness of aphasia in New Zealand. Aphasiology. 2013;27(5):568-80.

9. Babbitt E, Cherney L, Halper A. Measuring changes in quality of life in persons with aphasia: Is communication confidence a good measure? [Conference Paper]. Presented at the Clinical Aphasiology Conference: Jackson Hole, WY, USA. 2008 May 27-Jun 01. Available from: http://aphasiology.pitt.edu/id/eprint/1906.

10. Ali N, Rafi MS, Khan MSG, Mahfooz U. The effectiveness of script training to restore lost communication in a patient with Broca's aphasia. J Pak Med Assoc. 2018 Jul;68(7):1070-5.

11. Azhar A, Maqbool S, Butt G, Iftikhar S, Iftikhar G. Frequency of aphasia and its symptoms in stroke patients. J Speech Pathol Ther. 2017;2(1):121.

12. Davidson B, Howe T, Worrall L, Hickson L, Togher L. Social participation for older people with aphasia: the impact of communication disability on friendships. Top Stroke Rehabil. 2008 JulAug;15(4):325-40.

13. Palmer R, Hughes H, Chater T. What do people with aphasia want to be able to say? A content analysis of words identified as personally relevant by people with aphasia. PloS one. 2017;12(3): 0174065 .

14. Brodin J, Magnusson M. Still picture telephones for people with aphasia and mental retardation. Stockholm University (Sweden). Dept. of Education Technolology, Communication \& Disability. Report No. 4. 1992. Available from:

https://files.eric.ed.gov/fulltext/ED348796. pdf.

15. Starkstein SE, Robinson RG. Aphasia and depression. Aphasiology. 1988;2(1):1-19. Published Online 2007 May 29. Available from:

https://doi.org/10.1080/026870388082488 83.

16. Kim ES, Suleman S, Hopper T. Decision making by people with aphasia: a comparison of linguistic and nonlinguistic measures. J Speech Lang Hear Res. 2020 Jun 22;63(6): 1845-60

17. Rowland A, McDonald L. Evaluation of social work communication skills to allow people with aphasia to be part of the decision making process in healthcare. Soc Work Edu. 2009 Feb;28(2):128-44

18. Hilari K, Cruice M, Sorin-Peters R, Worrall L. Quality of life in aphasia: state of the art. Folia Phoniatr Logop. 2015;67:114-8. 